\title{
Isomerization and Fragmentation of Methyl Benzofuran Ions and Chromene Ions in the Gas Phase
}

Rüdiger Spilker and Hans-Fr. Grützmacher

Fakultät für Chemie, Universität Bielefeld, Universitätsstrasse 25, D-4800 Bielefeld 1, FRG

\begin{abstract}
The rearrangement of the molecular ions of the isomeric 2- and 3-methyl benzofurans (1 and 2), 2H-chromene (3) and $4 \mathrm{H}$-chromene (4) has been studied as a further example of the isomerization of oxygen-heteroaromatic radical cations via a ring expansion/ring contraction mechanism well documented for molecular ions of alkyl benzenes. The ions $1^{+\cdot}-4^{+\cdot}$ fragment mainly by $H$ loss into identical chromylium ions $a$. The process exhibits consistently a large kinetic energy release and an isotope effect $k_{\mathrm{H}} / k_{\mathrm{D}}$, which arise from a rate-determining energy barrier of the last dissociation step. Differences of the kinetic energy releases, the isotope effects and the appearance energies of the methyl benzofuran ions and the chromene ions indicate a large energy barrier also for the initial hydrogen migration during the rearrangement of the methyl benzofuran ions. This is substantiated by an MNDO calculation of the minimum energy reaction path. In contrast to the behaviour of alkyl benzene ions, a unidirectional isomerization of the methyl benzofuran ions by ring expansion takes place but no mutual interconversion of the molecular ions of methyl benzofurans and chromenes.
\end{abstract}

\section{INTRODUCTION}

The mass spectra of aromatic compounds have attracted considerable interest in connection with the analytical application of mass spectrometry to this important class of compounds and because of the interesting gas-phase ion chemistry of aromatic ions. ${ }^{1}$ The mutual interconversion of the molecular ions of toluene and cycloheptatriene and the related isomerizations of the molecular ions of isomeric alkylbenzenes are very likely to be the most popular examples of skeletal rearrangements of organic ions. The mechanisms of these rearrangements have been studied in great detail by a variety of mass spectrometric and computational techniques. $^{2}$

Many natural compounds belong to the important subgroup of heteroaromatic compounds, and heteroarenes are of widespread use for pharmaceutical and technical purposes. Consequently the electron impact (EI) mass spectra of many heteroaromatic substances have been collected and commented upon. ${ }^{3}$ In spite of this the exact mechanisms of the mass spectral fragmentations of these compounds are not well known. Usually it is postulated that the unimolecular fragmentations of heteroaromatic ions follow closely the mechanisms of the corresponding benzene ions. ${ }^{\mathbf{a}, \mathbf{b}}$ In particular it is assumed that a mutual interconversion of the molecular ions of isomeric alkyl heteroarenes with five- and sixmembered rings occurs by ring expansion/ring contraction processes in close analogy to the isomerization of toluene and cycloheptatriene ions. However, the $70 \mathrm{eV}$ mass spectra of the positional isomers of alkyl heteroarenes are usually more different from those of isomeric alkyl benzenes, contradicting the postulated equili- bration of isomeric molecular ions. The $70 \mathrm{eV}$ mass spectra of methylated furans, for example, exhibit an increasing intensity of the acetyl cation at $\mathrm{m} / \mathrm{z} 43$ with the number of methyl substituents at the $\alpha$-position. ${ }^{4}$ Clearly a more detailed study of the gas-phase ion chemistry of heteroaromatic ions related to alkyl benzene ions is needed to understand the analogies and differences in the mass spectrometric behaviour of these compounds.

The gas-phase reactions of the molecular ions and of the protonated molecules, respectively, of methylated furans, the isomeric pyrans and of some linear isomers have been studied recently. ${ }^{5,6}$ Although the results prove clearly the occurrence of isomerization reactions they show that no equilibration takes place between the isomeric ions of the furan and pyran series before the fragmentation, in contrast to the equilibrating system of toluene and cycloheptatriene ions. The loss of a hydrogen atom from metastable molecular ions $\left[\mathrm{C}_{5} \mathrm{H}_{6} \mathrm{O}\right]^{+\cdot}$ of 2- and 3-methyl furan and 4H-pyran gives rise to broad flat-topped peaks in the mass-analysed ion kinetic energy (MIKE) spectra, ${ }^{5 a}$ again contrasting the behaviour of the alkyl benzene ions. Furthermore, an isotope effect is observed for the $\mathrm{H} / \mathrm{D}$-exchange within deuterated metastable methyl furan ions, and apparently only minor $\mathrm{H} / \mathrm{D}$-migrations occur in metastable 2,5 -dideutero-4H-pyran ions prior to decomposition. ${ }^{5 a}$ Obviously the potential energy surfaces of the isomerization and fragmentation reactions of these heteroaromatic ions are distinctly different from that of alkyl benzene ions, in spite of a similar formal description of the reaction mechanisms in both cases.

The lack of extensive hydrogen migrations within the molecular ions of $4 \mathrm{H}$-pyrans is derived from the preferred loss of $\mathrm{H}$ from the metastable 2,5-dideutero- $4 \mathrm{H}$ - 
pyran ions and corroborated by the nearly specific loss of $\mathrm{H}$ and $\mathrm{CH}_{3}$, respectively, from metastable 3-methyland 4-methyl-4H-pyran ions. This behaviour is especially intriguing in view of the complete exchange ('scrambling') of $\mathrm{H}$ - and $\mathrm{D}$-atoms in the deuterated methyl furan ions. Unfortunately, this effect cannot be studied in detail because of the thermal instability of the unsubstituted $4 \mathrm{H}$ - and $2 \mathrm{H}$-pyran complicating the synthesis of deuterated derivatives. However, the corresponding benzo derivatives, i.e. $2 \mathrm{H}$ - and $4 \mathrm{H}$-chromene, are well-known stable compounds. Hence we extended our studies of the gas-phase reactions of heteroaromatic ions to the molecular ions of $2 \mathrm{H}$ - and $4 \mathrm{H}$-chromene and of the isomeric 2-methyl and 3-methyl benzofuran.

The $70 \mathrm{eV}$ mass spectra of $2 \mathrm{H}$ - and $4 \mathrm{H}$-chromene, of benzofuran and of its alkylated derivatives and some related compounds have been reported previously. ${ }^{7}$ It is obvious from these spectra that excessive rearrangements accompany the unimolecular fragmentations of the corresponding molecular ions; a typical example is the loss of $\mathrm{CO}$ from the 2,3-dimethyl benzofuran ions. ${ }^{7 \mathrm{a}}$ Another common feature of these mass spectra is the tendency to form $\left[\mathrm{C}_{9} \mathrm{H}_{7} \mathrm{O}\right]^{+}$ions which are apparently benzopyrylium ('chromylium') ions. An interesting example is the ring contraction of the 2,3-dihydrobenzoxepin ion. ${ }^{7 \mathrm{c}}$ The formation of $\left[\mathrm{C}_{9} \mathrm{H}_{7} \mathrm{O}\right]^{+}$ions give rise to abundant losses of an $\mathrm{H}$-atom from the molecular ions of the isomeric chromenes and methyl benzofurans. In this paper we report the results of a detailed study of this latter reaction. We will show that the anticipated chromylium ions are indeed formed by rearrangement reactions of the molecular ions, but that the relative activation energies and rates of the competing rearrangements and fragmentations are different from the comparable carba system.

\section{RESULTS AND DISCUSSION}

The $70 \mathrm{eV}$ mass spectra of 2-methyl benzofuran (1), 3methylbenzofuran (2), 2H-chromene (3) and 4Hchromene (4) (Scheme 1) are very similar, as noted before. $^{7 \mathrm{a}, \mathrm{b}}$ The base peak is due to the $[\mathrm{M}-\mathrm{H}]^{+}$ions $\left[\mathrm{C}_{9} \mathrm{H}_{7} \mathrm{O}\right]^{+}, m / z 131$, and besides the molecular ions (45-90\% relative intensity) characteristic fragment ions are only observed at $m / z 103[\mathrm{M}-\mathrm{CHO}]^{+}, 10-25 \%$ relative intensity) and $m / z 77\left(\left[\mathrm{C}_{6} \mathrm{H}_{5}\right]^{+}, 15-25 \%\right.$ relative intensity). The structure of a chromylium ion $a$ is assigned to the $\left[\mathrm{C}_{9} \mathrm{H}_{7} \mathrm{O}\right]^{+}$ions, but the formation of

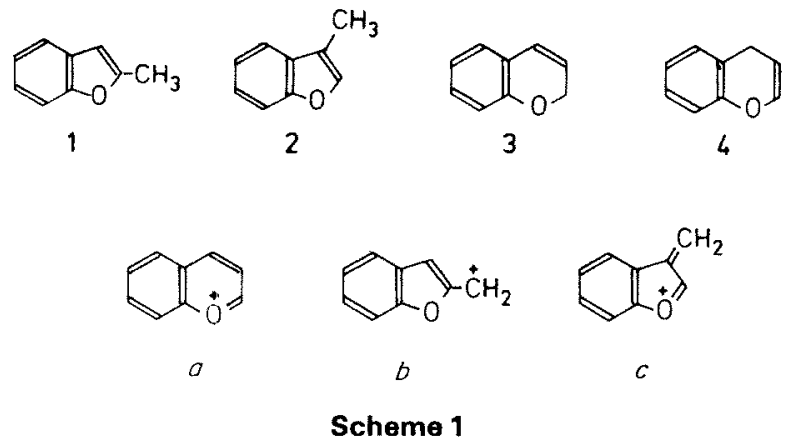

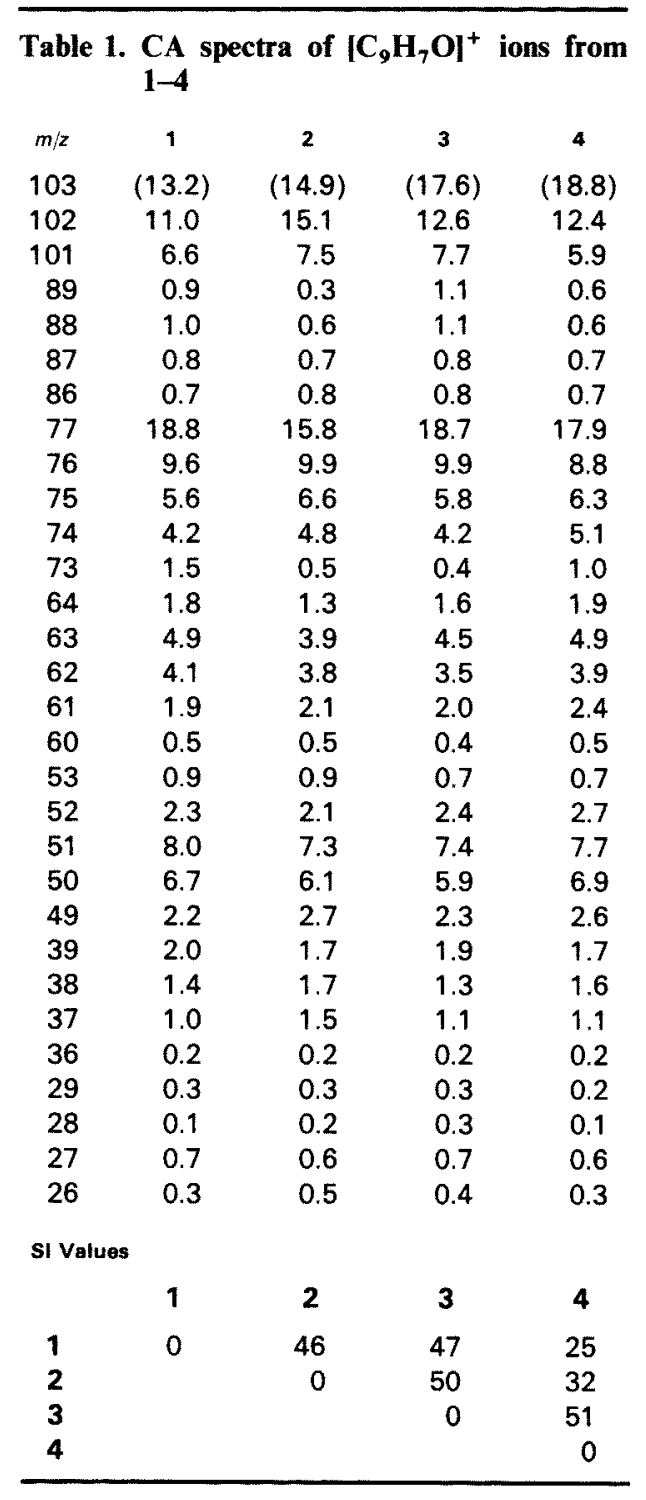

2-methene benzofuranyl ions $b$ and 3-methene benzofuranyl ions $c$, respectively, cannot be excluded $a$ priori for 1 and $2^{7 a}$ (Scheme 1). In this connection it should be noted that the loss of $\mathrm{H}$ occurs less readily from the methyl benzofuran ions $(\mathrm{M} /[\mathrm{M}-\mathrm{H}] \mathbf{1}: 0,82 ; 2: 0,75$; 3: 0,$36 ; 4: 0,46)$.

The structure of the product ions $\left[\mathrm{C}_{9} \mathrm{H}_{7} \mathrm{O}\right]^{+}$from 1-4 has been investigated by two methods. Firstly the collisional activation (CA) spectra of the $\left[\mathrm{C}_{9} \mathrm{H}_{7} \mathrm{O}\right]^{+}$ ions are very similar (Table 1 ). Small differences are observed for the relative abundances of the fragment ions at $m / z 103,102$ and 77. The loss of $\mathrm{CO}(\mathrm{m} / z \mathrm{103})$ is by far the main spontaneous fragmentation of the $\left[\mathrm{C}_{9} \mathrm{H}_{7} \mathrm{O}\right]^{+}$ions and the intensity differences in the CA spectra are very likely due to different contributions of this spontaneous reaction. The small differences of the relative abundances of ions at $m / z 102$ and 77 do not correlate with the different $\mathrm{C}$-skeleton of the parent ions, but the extreme values occur with the two benzofurans 1 and 2. A more objective comparison of CA spectra differing only in peak intensities is possible by using similarity indices (SI). ${ }^{8}$ In the present case the similarity indices of the CA spectra are below 51, which 


\begin{tabular}{|c|c|c|c|c|c|c|c|}
\hline & 1 & 2 & 3 & 4 & $\mathbf{a}$ & b & c \\
\hline$\Delta H_{f}$ (neutral) & -27 & -29 & -21 & -27 & - & - & - \\
\hline$\Delta H_{f}$ (ion) & 770 & 775 & 770 & 775 & 716 & 808 & 800 \\
\hline$I E^{\mathrm{a}}$ & 797 & 804 & 791 & 802 & & & \\
\hline$I E^{\mathrm{b}}$ & 808 & 815 & 783 & 799 & & & \\
\hline$A E\left(\left[\mathrm{C}_{9} \mathrm{H}_{7} \mathrm{O}\right]^{+}\right)$ & 1145 & 1124 & 988 & 1008 & & & \\
\hline$\Delta H_{f}\left(\left[\mathrm{C}_{9} \mathrm{H}_{7} \mathrm{O}\right]^{+}\right)+\varepsilon^{*}$ & 954 & 935 & 791 & 817 & & & \\
\hline$\Delta H_{f}\left(\left[\mathrm{C}_{9} \mathrm{H}_{7} \mathrm{O}\right]^{+}\right)_{\text {corr }}$ & 928 & 909 & 765 & 791 & & & \\
\hline $\begin{array}{l}\text { a Calculated by MNDC } \\
\text { - Experimental. }\end{array}$ & & & & & & & \\
\hline
\end{tabular}

indicates for this class of ions indistinguishable spectra and hence identical structures (or mixtures) for the $\left[\mathrm{C}_{9} \mathrm{H}_{7} \mathrm{O}\right]^{+}$ions. $^{9}$

Secondly, the appearance energies $(A E)$ of the $\left[\mathrm{C}_{9} \mathrm{H}_{7} \mathrm{O}\right]^{+}$ions from 1-4, respectively, have been determined by the semilog-plot method ${ }^{10}$ using modified instrumentation. ${ }^{5 \mathrm{a}}$ The values obtained are presented in Table 2, together with the experimental ionization energy (IE) of 1-4 and some relevant thermochemical data. The $A E$ s determined by the semilog method are reproducible to about $0.1 \mathrm{eV}$ but the values obtained by this technique are usually too large because of systematic errors. However, in the present case the AEs are used only to differentiate between the strctures $a, b$ and $c$ of the $\left[\mathrm{C}_{9} \mathrm{H}_{7} \mathrm{O}\right]^{+}$product ions, and it is sufficient to show that the experimental $\Delta H_{\mathrm{f}}\left(\left[\mathrm{C}_{9} \mathrm{H}_{7} \mathrm{O}\right]^{+}\right)$falls below the values calculated for the energy-rich isomers $b$ and $c$ (see Fig. 1). The heats of formation $\Delta H_{\mathrm{f}}$ of 1-4 are needed and have been calculated by the MNDO method. ${ }^{11}$ It is known that a calculation of $\Delta H_{\mathrm{f}}$ by MNDO may include systematic errors. ${ }^{12}$ In the present case the stability of the six-membered heterocycles is very likely exaggerated by the MNDO method. ${ }^{5 a, 9}$ To test the reliability of the $\Delta H_{\mathrm{f}}$ values calculated by MNDO, the ionization energies (IEs) of 1-4 have also been obtained by MNDO via the differences of the $\Delta H_{\mathrm{f}} \mathrm{s}$ of the molecular ions and the neutral molecules. The results (Table 2) agree reasonably well with the experimental IE. Hence the same systematic error occurs obviously in the calculations of the $\Delta H_{\mathrm{f}} \mathrm{s}$ of the ions and the neutrals, and the MNDO values can be used in the present discussion of relative energies with some confidence.

The $A E$ s are related to the $\Delta H_{\mathrm{f}}\left(\left[\mathrm{C}_{9} \mathrm{H}_{7} \mathrm{O}\right]^{+}\right)$by the following equation:

$$
A E=\Delta H_{\mathrm{f}}\left(\left[\mathrm{C}_{9} \mathrm{H}_{7} \mathrm{O}\right]^{+}\right)+\Delta H_{\mathrm{f}}(\mathrm{H})-\Delta H_{\mathrm{f}}\left(\mathrm{C}_{9} \mathrm{H}_{8} \mathrm{O}\right)+\varepsilon^{*}
$$

Using $\Delta H_{\mathrm{f}}\left(\mathrm{H}^{*}\right)=218 \mathrm{~kJ} \mathrm{~mol}^{-113}$ and the $\Delta H_{\mathrm{f}}\left(\mathrm{C}_{9} \mathrm{H}_{8} \mathrm{O}\right)$ obtained by MNDO, $\left(\Delta H_{\mathrm{f}}\left(\left[\mathrm{C}_{9} \mathrm{H}_{7} \mathrm{O}\right]^{+}\right)+\varepsilon^{*}\right)$ has been calculated (Table 2). The magnitude of the total excess internal energy $\varepsilon^{*}$ of the fragment ions is not known, but a mean kinetic energy release (KER) of $26 \pm 3 \mathrm{~kJ}$ $\mathrm{mol}^{-1}$ is measured for the loss of $\mathrm{H}$ from $\mathbf{1}^{+\cdot}-4^{+\cdot}$ (see below). Taking this KER into account a $\Delta H_{\mathrm{f}}\left(\left[\mathrm{C}_{9} \mathrm{H}_{7} \mathrm{O}\right]^{+}\right) \leqslant 764$ and $\leqslant 790 \mathrm{~kJ} \mathrm{~mol}^{-1}$, respectively, is obtained for 3 and 4. This upper limit of $\left.\Delta H_{\mathrm{f}}\left[\mathrm{C}_{9} \mathrm{H}_{7} \mathrm{O}\right]^{+}\right)$is below the values estimated for the methene benzofuranyl cations $b$ and $c$. Even accounting for the experimental and computational errors of the
$\Delta H_{\mathrm{f}}$ values, this is only in accord with a chromylium structure $a$ for the product ions; at least for 3 but very likely also for 4 . The $\Delta H_{\mathrm{f}}\left(\left[\mathrm{C}_{9} \mathrm{H}_{7} \mathrm{O}\right]^{+}\right) \leqslant 927$ and $\leqslant 908$ $\mathrm{kJ} \mathrm{mol}^{-1}$, respectively, for 1 and 2 is compatible with the formation of chromylium ions $a$ and the methene benzofuranyl cations $b$ and $c$. However, identical $\left[\mathrm{C}_{9} \mathrm{H}_{7} \mathrm{O}\right]^{+}$ions are formed by $1-4$, as evidenced by identical CA spectra, hence these productions $\left[\mathrm{C}_{9} \mathrm{H}_{7} \mathrm{O}\right]^{+}$correspond to chromylium ions $a$ for all compounds.

The formation of chromylium ions $a$ from the methyl benzofurans 1 and 2 requires a rearrangement of the molecular ions into a chromene radical cation before the loss of $\mathrm{H}^{14}$ For metastable $\mathrm{1}^{+\cdot}$ and $2^{+}$, respectively, this reaction gives rise to broad and nearly flattopped peaks in the MIKE spectra and the KER values obtained from the peak width at $50 \%$ intensity $\left(T_{50}\right)$ are shown in Table 3. This observation as well as the larger $A E$ s for the $\left[\mathrm{C}_{9} \mathrm{H}_{7} \mathrm{O}\right]^{+}$ions from 1 and 2 would agree with a reaction energy determining rearrangement step preceding the elimination of $\mathbf{H}$ and giving rise to a reverse critical energy. However, broad and flat-topped peaks and similar KERs (Table 3) are observed also for the loss of $\mathrm{H}$ from the metastable chromene ions $3^{+}$ and $4^{+}$. The origin of the KER is therefore not an energy barrier of the rearrangement but a reverse activation energy of the last dissociation step. The same situation has been observed for the elimination of $\mathrm{H}$ from the molecular ions of methyl furans and $4 \mathrm{H}-$ pyran, ${ }^{5 a}$ respectively, and in fact, the KERs for these latter processes are very similar to those observed here.

Further examples for a large and non-statistical KER accompanying a direct bond cleavage are the losses of $\mathrm{CH}_{3}$ from metastable molecular ions of tetramethyl $4 \mathrm{H}-$ and $2 \mathrm{H}$-pyran ${ }^{\text {sc }}$ and of 2,2-dimethyl chromene. ${ }^{15}$ It appears that in all these cases the geometry within the rings of the parent ions and of the fragment ions, respectively, is very different, and that this difference provokes the reverse activation barrier of the direct bond dissociation. The geometries of the molecular ions of 1-4 and of the $\left[\mathrm{C}_{9} \mathrm{H}_{7} \mathrm{O}\right]^{+}$ions are shown in Fig. 1. The effect of the different bond lengths within the oxy-

Table 3. Kinetic energy release for the elimination of $\mathrm{H}$ from $1^{+\cdot}-4^{+\cdot}$

\begin{tabular}{ccccc} 
& 1 & 2 & 3 & 4 \\
$T_{50}\left(\mathrm{~kJ} \mathrm{~mol}^{-1}\right)$ & 28 & 39 & 25 & 23 \\
\hline
\end{tabular}




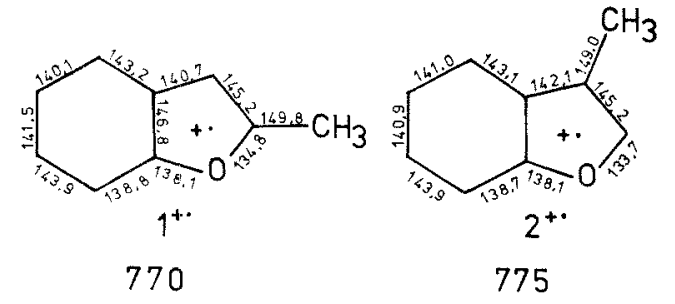<smiles>C1=CCC2CCCCC2C=C1</smiles>

770<smiles></smiles>

$b$ 808

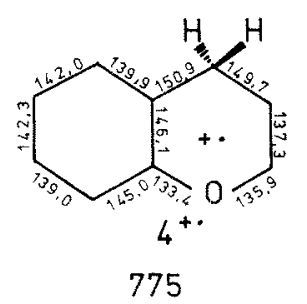

775<smiles>C1=CC2CCCCCC2OC1</smiles>

716

Figure 1. Geometry (MNDO) of $\left[\mathrm{C}_{9} \mathrm{H}_{8} \mathrm{O}\right]^{+\cdot}$ ions and $\left[\mathrm{C}_{9} \mathrm{H}_{7} \mathrm{O}\right]^{+}$ ions.

genated rings of the chromene parent ions and the chromylium fragment ions is clearly seen.

Following from this explanation for the large KER during the formation of the chromylium ion $a$ from $1^{+\cdot}-4^{+*}$, the increase of the $A E s$ of this process for $1^{+}$ and $2^{+\cdot}$ must be due to a large kinetic shift and a slow and entropically unfavourable rearrangement preceding the loss of $\mathrm{H}$. A fraction of the non-fixed excess energy of the rearranged ions appears as some additional translational energy of the fragments, giving rise to further peak broadening in the MIKE spectra and moderately larger KERs for $1^{+*}$ and $2^{+*}$.

The loss of the structural integrity of $1^{+\cdot}-4^{+\cdot}$ by possible mutual interconversion has been further tested by the CA spectra of the molecular ions. Ions of a longer life-time are sampled by this technique and any isomerization reactions may have proceeded until equilibration. In fact, the $\mathrm{CA}$ spectra of the $\left[\mathrm{C}_{9} \mathrm{H}_{3} \mathrm{O}\right]^{+\cdot}$ ions $2^{+\cdot}-4^{+\cdot}$ cannot be distingushed within the limits of error as indicated by the SI values $\leqslant 50$ (Table 4). However, the CA spectrum of the molecular ion of 2methyl benzofuran (1) contains a small but unique peak at $m / z 43$ of $\left[\mathrm{CH}_{3} \mathrm{CO}\right]^{+}$ions, which is typically of a 2-methyl furan unit in the molecular ions ${ }^{4,5 a}$ and which are also observed in the $70 \mathrm{eV}$ mass spectra.

There are several explanations for this result, but in

\begin{tabular}{|c|c|c|c|c|}
\hline \multicolumn{5}{|c|}{ Table 4. CA spectra of $1^{+\cdot}-4^{+\cdot}$} \\
\hline$m / z$ & 1 & 2 & 3 & 4 \\
\hline 131 & $(248)$ & $(234)$ & $(376)$ & $(426)$ \\
\hline 104 & 4.7 & 7.0 & 7.1 & 7.1 \\
\hline 103 & 11.3 & 13.6 & 12.6 & 12.5 \\
\hline 102 & 10.2 & 10.1 & 10.3 & 10.1 \\
\hline 89 & 2.3 & 1.2 & 1.2 & 1.2 \\
\hline 88 & 2.3 & 1.2 & 1.2 & 1.2 \\
\hline 87 & 1.2 & 1.2 & 1.2 & 1.2 \\
\hline 86 & 1.2 & 1.2 & 1.2 & 1.2 \\
\hline 78 & 5.8 & 3.5 & 4.7 & 4.7 \\
\hline 77 & 15.0 & 12.4 & 12.6 & 13.7 \\
\hline 76 & 3.5 & 7.0 & 7.1 & 7.1 \\
\hline 75 & 2.3 & 3.5 & 2.4 & 3.5 \\
\hline 74 & 1.2 & 3.5 & 2.4 & 3.5 \\
\hline 64 & 2.3 & 2.3 & 2.4 & 1.2 \\
\hline 63 & 5.8 & 4.7 & 4.7 & 3.5 \\
\hline 62 & 4.7 & 3.5 & 3.5 & 3.5 \\
\hline 61 & 2.3 & 2.3 & 1.2 & 1.2 \\
\hline 52 & 2.3 & 2.3 & 3.5 & 3.5 \\
\hline 51 & 6.9 & 5.8 & 7.0 & 7.1 \\
\hline 50 & 4.7 & 4.7 & 4.7 & 4.7 \\
\hline 49 & 2.3 & 2.3 & 2.4 & 2.4 \\
\hline 43 & 2.3 & - & - & - \\
\hline 39 & 2.3 & 2.3 & 2.4 & 2.4 \\
\hline 38 & 1.2 & 2.3 & 1.2 & 1.2 \\
\hline 37 & 1.2 & 1.2 & 1.2 & 1.2 \\
\hline 28 & 0.3 & 0.4 & 0.3 & 0.4 \\
\hline 27 & 0.2 & 0.2 & 0.2 & 0.3 \\
\hline \multicolumn{5}{|c|}{ SI values (neglecting signal at $m / 2$ 43) } \\
\hline & 1 & 2 & 3 & 4 \\
\hline 1 & 0 & 63 & 51 & 67 \\
\hline 2 & & 0 & 33 & 38 \\
\hline 3 & & & 0 & 24 \\
\hline 4 & & & & 0 \\
\hline
\end{tabular}

any case a complete mutual interconversion of the $\left[\mathrm{C}_{9} \mathrm{H}_{8} \mathrm{O}\right]^{+\cdot}$ ions is excluded, since ions with a 2 -methyl benzofuran structure (1) are not formed by $2^{+*}-4^{+*}$. Neglecting the peak at $m / z 43$, the CA spectrum of $1^{+*}$ is again very similar to the other ones (SI values $\simeq 60$, Table 4). We suggest therefore that some of the methyl benzofuran ions $1^{+}$and $2^{+*}$ retain their structure (or fragment via ring-opened isomers), but that there is a unidirectional isomerization of the benzofuran ions into chromene ions preceding the elimination of $\mathrm{H}$ and most of the other fragmentation reactions. This is corroborated by the results of labelling experiments.

The formulae of the deuterated analogues of 1-4 are shown in Scheme 2. The MIKE spectrum of each of these deuterated molecular ions (Table 5) exhibits large signals for the losses of $\mathrm{H}$ and $\mathrm{D}$, and a small peak for the elimination of $\mathrm{CO}$.

There are two significant observations. The first one is the loss of $\mathrm{H}$ and $\mathrm{D}$ from all metastable deuterated molecular ions. Nearly equal amounts of $H$ and $D$ are lost from the trideuteromethyl benzofurans $1 \mathrm{a}$ and 2a. A direct dissociation of one of the $\mathrm{H}$ atoms at the aromatic rings is very unfavourable, hence the abundant losses of $\mathrm{H}$ from these molecular ions indicate considerable rearrangement at least by $H / D$ migration if not by skeletal isomerization. H/D migrations are also recognized from the MIKE spectra of $\mathbf{3 a}$ and $\mathbf{4 a}$, which expel 


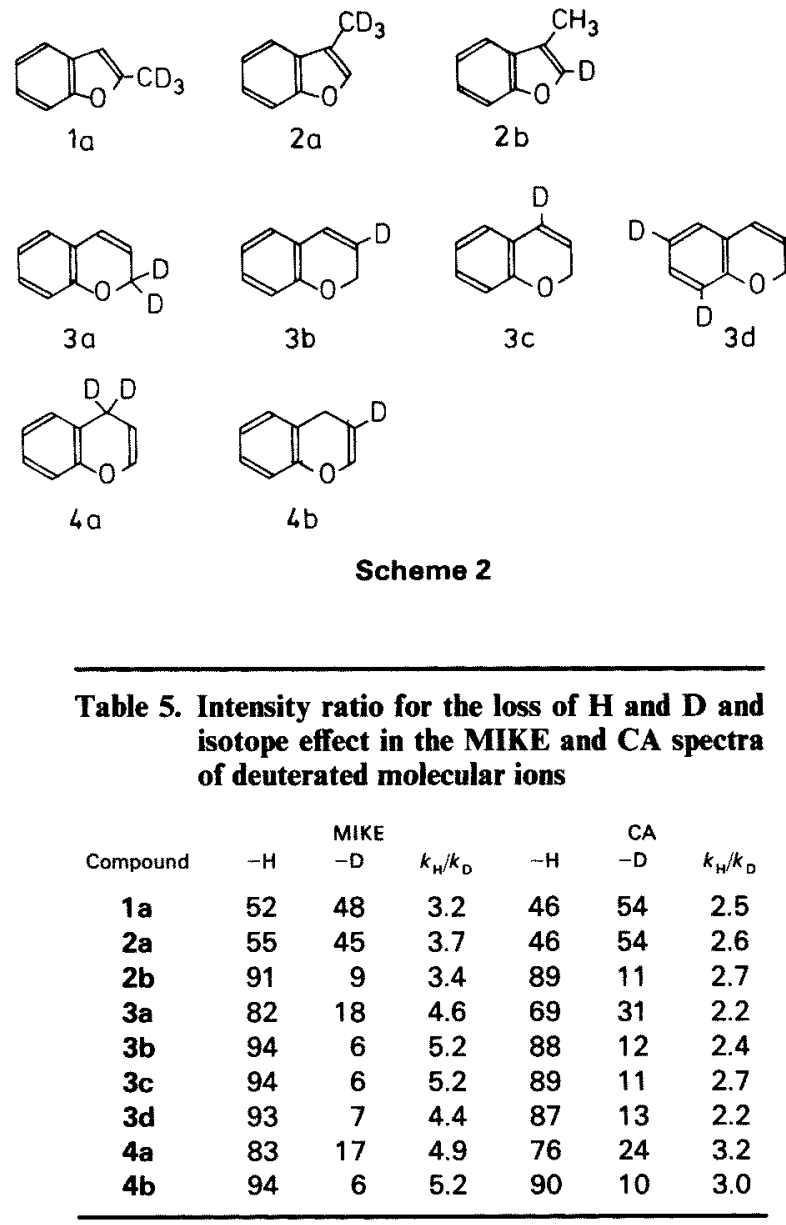

mainly an $\mathrm{H}$ atom instead of a $\mathrm{D}$ atom from the 2- and 4-position, respectively, expected in the case of a direct formation of the chromylium ion. Finally, the ratio for the loss of $\mathrm{H}$ and $\mathrm{D}$ from $3 \mathrm{~b}^{+\cdot}$ and $3 \mathrm{~d}^{+\cdot}$ is identical within the limits of error, excluding any H/D-exchange between the positions at the oxygenated ring and the benzo group. Thus all hydrogen atoms of the methyl group and at the oxygenated ring, but not of the benzo group, take part in the elimination of $\mathrm{H}$. This is only possible by excessive rearrangements within the heterocyclic moiety of the ions.

The second important observation is the large isotope effect for the loss of $D$ from all metastable deuterated ions. This follows from the large deviations of the experimental ratio $[\mathrm{M}-\mathrm{H}]:[\mathrm{M}-\mathrm{D}]$ (Table 5) from the statistical distribution of $H$ and $D$ atoms (excluding the $4 \mathrm{H}$ atoms at the benzo group, see above). These deviations are not due to the elimination of a unique $\mathrm{H}$ or D atom, which is most easily seen by the results from the 'inverse' isotopomers $\mathbf{2 a}$ and $\mathbf{2 b}$, both exhibiting $\mathbf{a}$ discrimination for the loss of D. Isotope effects $k_{\mathrm{H}} / k_{\mathrm{D}}$ of $3.5 \pm 0.3$ and $4.9 \pm 0.5$, respectively, have been calculated for the fragmentation of the methyl benzofuran ions and the chromene ions (Table 5). Note that the isotope effects are distinctly smaller for metastable methyl benzofuran ions. This can be assigned to a larger mean internal energy of the fragmenting $\left[\mathrm{C}_{9} \mathrm{H}_{8} \mathrm{O}\right]^{+}$. ions derived from 1 and 2 . Obviously these $\left[\mathrm{C}_{9} \mathrm{H}_{8} \mathrm{O}\right]^{+*}$ ions correspond to chromene ions chemically activated by the skeletal rearrangement of $1^{+\cdot}$ and $2^{+\bullet}$. The isotope effect $k_{\mathrm{H}} / k_{\mathrm{D}}$ is clearly sensitive to the excess energy of the ions studied. This is illustrated by the isotope effects calculated from the losses of $H$ and $D$ in the CA spectra of deuterated molecular ions (Table 5). An average value $2.6 \pm 0.4$ of the isotope effect is obtained without any separation between methyl benzofuran ions and chromene ions. ${ }^{16}$ The formation of $\left[\mathrm{C}_{9} \mathrm{H}_{8} \mathrm{O}\right]^{+\cdot}$ with extra internal energy from 1 and 2 has been inferred already from the increased KER during the elimination of $\mathrm{H}$ and the larger $A E \mathrm{~s}$ of the $[\mathrm{M}-\mathrm{H}]^{+}$ions. Thus, the results obtained by different mass spectroscopic techniques are in excellent agreement and point convincingly to some specific features of the reaction energy profile of the isomerizations and fragmentations of methyl benzofuran ions and chromene ions. The KER and the isotope effect manifest a large critical energy barrier for the elimination of $\mathrm{H}$ from the $2 \mathrm{H}$ - and $4 \mathrm{H}$-chromene ions while the unidirectional isomerization of the methyl benzofuran ions and the formation of chemically activated $\left[\mathrm{C}_{9} \mathrm{H}_{8} \mathrm{O}\right]^{+}$ions demonstrate that the critical energy of at least the rearrangement steps is similar to the barrier of the final fragmentation.

The minimum energy reaction path (MERP) for the interconversion and fragmentation of $1^{+\cdot}-4^{+\cdot}$ has been calculated by MNDO. For convenience this MERP is shown in two parts in Fig. 2(a) and (b). These two MERPs are linked to each other by the $3 \mathrm{H}$-chromene ion $f$ which is the intermediate for the mutual interconversion of the $2 \mathrm{H}-$ and $4 \mathrm{H}$-chromene ions $3^{+\cdot}$ and $4^{+}$ by consecutive 1,2-H-shifts. ${ }^{17}$ The MNDO method is known to give frequently to large values for the potential energy of transition states of $\mathrm{H}$-migrations. ${ }^{18}$ Indeed, the calculated critical energies for the loss of $\mathrm{H}$ from $3^{+\cdot}$ and $4^{+}$, respectively, of 264 and $251 \mathrm{~kJ} \mathrm{~mol}^{-1}$ exceed the experimental $(A E-I E)$ values of 205 and $209 \mathrm{~kJ} \mathrm{~mol}^{-1}$, which can be regarded as the upper limit for the critical energies. Hence the quantitative aspects of the MERPs should not be overestimated. Nevertheless, qualitatively the calculated MERPs are in accord with the experimental facts. The main details are a very large critical energy $\left(360\right.$ and $330 \mathrm{~kJ} \mathrm{~mol}^{-1}$, respectively) for the direct elimination of $\mathrm{H}$ from the methyl benzofuran ions $1^{+\cdot}$ and $2^{+\cdot}$, creating the corresponding methene benzofuranyl cations $b$ and $c$. Consequently the rearrangement path of $\mathbf{1}^{+}$and $2^{+*}$ into the $3 \mathrm{H}$-chromene ion $f$ is favoured by about $100 \mathrm{~kJ} \mathrm{~mol}^{-1}$.

The MERP of the rearrangements of $1^{+\cdot}$ and $2^{+\cdot}$ has been formulated in close analogy to the toluene ion/ cycloheptatriene ion isomerization ${ }^{2 h, j, k}$ and consists of a 1,2-H shift from the methyl group on to the furan ring (ion $d$ and $d^{\prime}$ ), ring closure to a cyclopropano benzofuran structure (ion $e$ ) and eventually cleavage of the bond at the basis of the cyclopropane unit generating the $3 \mathrm{H}$ chromene ion $f$. The highest activation energy barrier along this rearrangement route is calculated for the initial 1,2-H shift. These barriers are only $10-20 \mathrm{~kJ}$ $\mathrm{mol}^{-1}$ below those of the fragmentations of the chromene ions. ${ }^{19}$ This fits very well with the observation of a unidirectional isomerization of the methyl benzofuran ions. The transition state for the initial $1,2-\mathrm{H}$ shift is 'tight', including a restriction of the free rotation of the methyl group. Consequently $\left[\mathrm{C}_{9} \mathrm{H}_{8} \mathrm{O}\right]^{+\cdot}$ ions from 1 

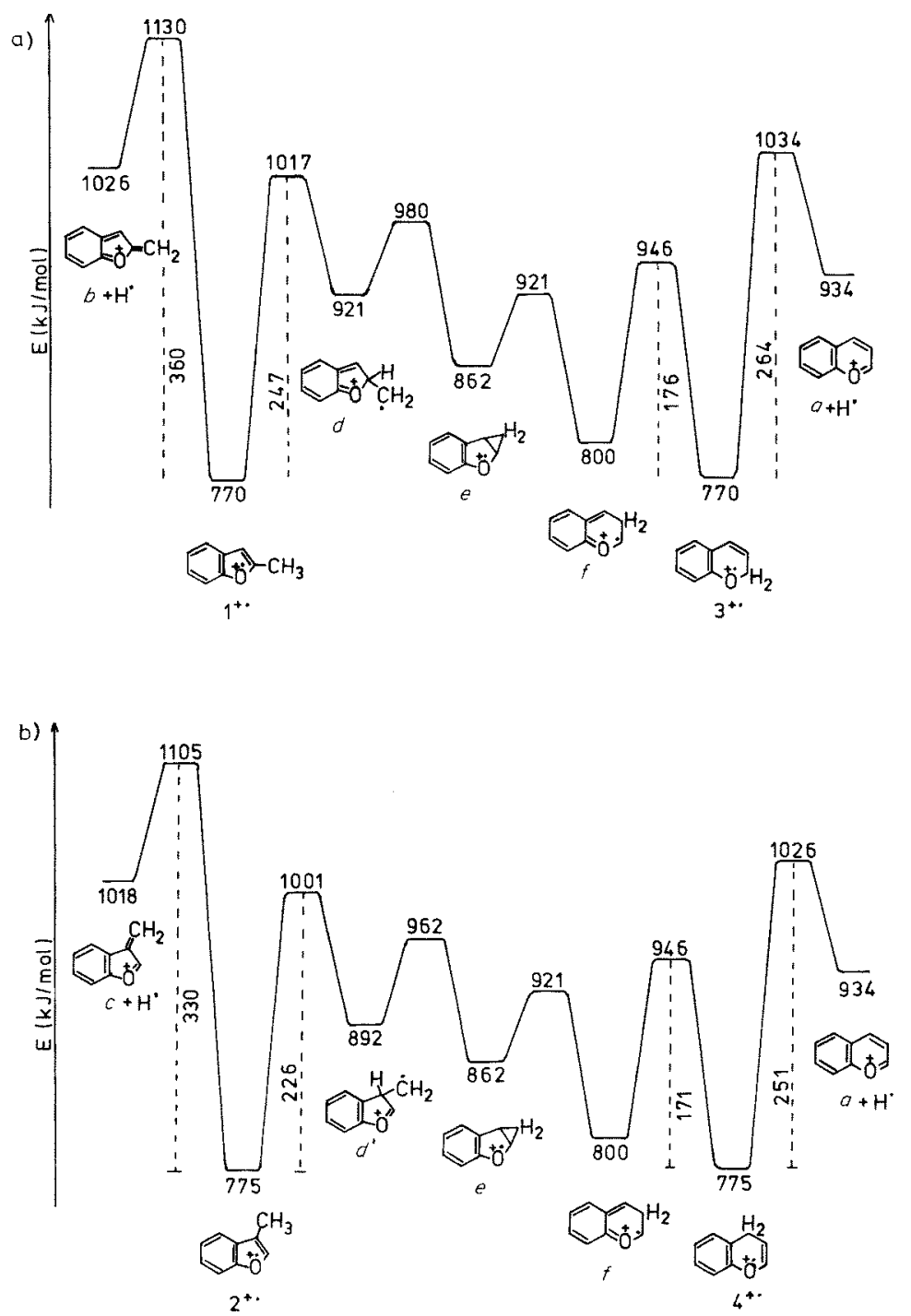

Figure 2. MERP (MNDO) for the isomerization and fragmentation of (a) $1^{+\cdot}$ and $3^{+*}$, and (b) $2^{+*}$ and $4^{+*}$.

and 2 with some excess energy select the forward reaction and eventually fragment into chromylium ions $a$ and $\mathrm{H}$. In the meantime they can explore the different wells of the MERPs, which results in extensive shuffling of the $\mathrm{H}$ atoms within the heterocyclic part of these ions.

\section{CONCLUSION}

The results of the present study of the mass spectral reactions of the molecular ions of the methyl benzofurans 1 and 2, and the chromenes 3 and 4 , reveal a close resemblance to the reactions of methyl furan ions and pyran ions. ${ }^{5 a}$ One observes a fragmentation of the ionized methyl furan compounds into stable pyrylium ions by a skeletal rearrangement for both systems supporting the usually assumed ring enlargement of alkylated heteroaromatic ions. However, these arrangements occur unidirectionally and no ring contraction into methylated five-membered heterocyclic structures is detected. An extensive H/D-exchange occurs within the heterocyclic part of the molecular ions of methyl benzo- furans and chromenes, albeit with a large isotope effect particularly in the case of the latter ions. While this concurs with the behaviour of the methyl furan ions ${ }^{5 a}$ it is not obvious from this result whether an $H / D$ exchange is actually absent in deuterated $4 \mathrm{H}$-pyran ions or whether this is simulated by an especially large isotope effect for the pyran ions. In any case, the large isotope effects measured for the H/D-exchange within chromene ions indicate distinct energy barriers for the 1,2-H-shifts within an ionized pyran moiety, comparable to those of the fragmentations.

The fast equilibration of toluene ions and cycloheptatriene ions is well established and the mutual interconversion of the molecular ions of other alkylated benzene ions and cycloheptatriene ions has been demonstrated. ${ }^{2}$ The oxygenated heteroaromatic molecular ions differ clearly from these carba compounds by the unidirectional isomerization of the ions containing a methyl furan unit. The experimental results and the MNDO calculation of the reaction energy profiles reveal that the source of this different behaviour of the heteroaromatic ions is a distinct barrier for the 1,2-H shift from the methyl substituent on to the heteroaromatic ring. In conjunction with the restrained $\mathrm{H}$ - 
shifts within the oxygenated rings it appears therefore that the main difference between the carbocyclic and heterocyclic aromatic molecular ions is a reduced tendency for hydrogen migrations within the latter ions so that 'direct' fragmentations from the original structures are also observed in the mass spectra.

\section{EXPERIMENTAL}

\section{Mass spectrometry}

The EI mass spectra were measured with a doublefocusing mass spectrometer MAT 311A in combination with a MAT SS 200 data system, using the following conditions: electron energy $70 \mathrm{eV}$, emitter current $3 \mathrm{~mA}$, acceleration voltage $3 \mathrm{kV}$, mass resolution about 1000 , ion source temperature about $180^{\circ} \mathrm{C}$, and sample introduction by a direct probe inlet system.

The MIKE and CA spectra were obtained with a double-focusing mass spectrometer VG ZAB 2F and the following experimental conditions: electron energy $70 \mathrm{eV}$, electron trap current $50 \mu \mathrm{A}$, acceleration voltage $6 \mathrm{kV}$, mass resolution about 1000 , ion source temperature $<200^{\circ} \mathrm{C}$, sample introduction by a direct probe inlet system. The reactions of metastable ions were studied by focusing magnetically the relevant ion into the second field-free region ( 2 nd FFR) and scanning the electrostatic field. The CA spectra were obtained by the same routine and introducing $\mathrm{He}$ into the collision cell of the second field-free region ( 2 nd FFR) at such a rate that the intensity of the main ion beam was cut down to $30-50 \%$. The ionization energies and appearance energies were measured with a modified VG MM 12 mass spectrometer described elsewhere ${ }^{5 a}$ using the semilog-plot method. ${ }^{10}$

\section{Compounds}

For the details of the synthesis of the methyl benzofurans and chromenes and their deuterated derivatives see Ref. 9. The compounds were chromatographically pure, and their structure has been verified by ${ }^{1} \mathrm{H}$ nuclear magnetic resonance.

2-Methyl benzofuran (1) was synthesized from benzofuran-2-carboxylic acid $^{20}$ in analogy to the method of D. I. Rawson. ${ }^{21}$

2-Trideuteromethyl benzofuran (1a) was prepared correspondingly by using $\mathrm{LiAlD}_{4}$. Deuterium content $\geqslant 95 \%$ (by mass spectrometry).
3-Methyl benzofuran (2) was obtained as described in the literature. ${ }^{22}$

3-Trideuteromethyl benzofuran (2a) was prepared from benzofuran-3-carboxylic acid ${ }^{23}$ by reduction with LiAlD $_{4} \cdot{ }^{22}$ Deuterium content $\geqslant 95 \%$ (by mass spectrometry).

2-Deutero-3-methyl benzofuran (2b) was synthesized by treatment of a solution of 2-bromo-3-methyl benzofuran ${ }^{24}$ in dry diethyl ether at $-70^{\circ} \mathrm{C}$ with an equimolar amount of Butyl-Li followed by addition of $\mathrm{D}_{2} \mathrm{O}$. Deuterium content $\geqslant 98$ (by mass spectrometry).

$2 \mathrm{H}$-chromene (3) was prepared by $\mathrm{CuSO}_{4}$-catalysed dehydration of 4-chromanol. ${ }^{25}$

2,2-Dideutero-2H-chromene (3a) was obtained in low yield from coumarin by reduction with $\mathrm{LiAlD}_{4}$. Deuterium content $\geqslant 95 \%$ (by mass spectrometry).

3-Deutero-2H-chromene (3b) was made by treatment of a solution of chroman-4-one in THF with dry $\mathrm{K}_{2} \mathrm{CO}_{3} / \mathrm{D}_{2} \mathrm{O}$, reduction of the resulting 3,3-dideutero chroman-4-one with $\mathrm{LiAlH}_{4}$ and dehydration of the 3,3-dideutero chroman-4-ol by heating with $\mathrm{CuSO}_{4}$. Deuterium content $\simeq 90 \%$ (by mass spectrometry).

4-Deutero-2H-chromene (3c) was obtained by dehydration of 4-deutero chroman-4-ol (from chroman-4-on with $\mathrm{LiAlD}_{4}$ ). Deuterium content $\geqslant 95 \%$ (by mass spectrometry).

3,6,8-Trideutero-2H-chromene (3d) was synthesized from 3,6,8,-trideutero coumarin $(\mathrm{H} / \mathrm{D}$-exchange of coumarin in a solution of $10 \% \mathrm{NaOD} / \mathrm{D}_{2} \mathrm{O}$ ) analogous to 3. Deuterium content $\simeq 90 \%$ (by mass spectrometry).

$4 \mathrm{H}$-chromen (4) was prepared from chroman-2-one $\left(\mathrm{H}_{2} / \mathrm{Ni}\right.$-hydrogenation of coumarin) by reduction with $\mathrm{LiAlH}\left(\mathrm{O} \text {-tert- } \mathrm{C}_{4} \mathrm{H}_{9}\right)_{3}$ to chroman-2-ol ${ }^{25}$ followed by dehydration.

4,4-Dideutero-4H-chromene (4a) was prepared from $o$-methoxy- $\alpha, \alpha$-dideutero benzyl malonic acid diethyl ester with $\mathrm{HBr}$ /acetic acid yielding 4,4-dideutero chroman-2-one followed by reduction and dehydration. Deuterium content $\geqslant 95 \%$ (by mass spectrometry).

2-Deutero-4H-chromene (4b) was obtained by the same method as the parent compound (4) but by using LiAlD $\left(\text { tert }-\mathrm{C}_{4} \mathrm{H}_{9}\right)_{3}$. Deuterium content $\geqslant 95 \%$ (by mass spectrometry).

\section{Acknowledgements}

The financial support by a grant of the Deutsche Forschungsgemeinschaft and by the Fonds der Chemischen Industrie is gratefully acknowledged. We thank Mr E. Gärtner, Fakultät für Chemie der Universität Bielefeld, for his assistance during the mass spectrometric measurements.

\section{REFERENCES}

1. (a) G. Spiteller, Massenspektrometrische Strukturanalyse organischer Verbindungen. Verlag Chemie, Weinheim (1966); (b) H. Budzikiewicz, C. Djerassi and D. H. Williams, Mass Spectrometry of Organic Compunds. Holden-Day, San Francisco (1967); (c) F. W. McLafferty, Interpretation of Mass Spectra (3rd edn). University Science Books, Mill Valley, California (1980).

2. (a) For a review see Mass Spectrometry, Specialist Periodical Reports, Vols 1-8, The Chemical Society, London (1971.
$1973,1975,1977,1979,1981,1983,1985$ ) (b) P. N. Rylander and S. Meyerson, J. Am. Chem. Soc. 78, 5794 (1956); (c) P. N. Rylander and S. Meyerson, J. Am. Chem. Soc. 79, 842 (1957); (d) S. Meyerson and P. N. Rylander, J. Org. Chem. 62, 2 (1958); (e) M. A. Baldwin, F. W. McLafferty and D. M. Jerina, J. Am. Chem. Soc. 97, 6169 (1975); (f) F. W. McLafferty and F. M. Bockhoff, Org. Mass Spectrom. 14, 181 (1979); (g) D. Kuck and H.-Fr. Grützmacher, Org. Mass Spectrom. 14, 86 (1979); (h) M. J. S. Dewar and D. 
Landman J Am Chem. Soc. 99, 2446 (1977): (i) B. J. Stapleton, R. D. Bowen and D. H. Williams, J. Chem. Soc., Perkin Trans 2, 1219 (1979); (j) J. Grotemeyer and H.-Fr. Grützmacher, in Current Topics in Mass Spectrometry and Chemical Kinetics, ed. by J. H. Beynon and M. L. McGlashan. Heyden, London (1982); (k) J. Grotemeyer and H.-Fr. Grützmacher, Org. Mass Spectrom. 17, 359 (1982).

3. (a) For a review see O. N. Porter and J. Baldas, Mass Spectrometry of Heterocyclic Compounds. Wiley, New York (1971); (b) see also the relevant chapters about the mass spectra of heterocyclic compounds and natural products in Ref. 2(a)

4. K. Heyns, R. Stute and H. Scharmann, Tetrahedron 22, 2223 (1966).

5. (a) R. Spilker and H.-Fr. Grützmacher, Org. Mass Spectrom. 21, 459 (1986): (b) H.-Fr. Grützmacher and R. Spilker, Org. Mass Spectrom. 20, 258 (1985); (c) J. Grotemeyer and H.-Fr. Grützmacher, Int. J. Mass Spectrom. Ion Phys. 47, 399 (1983).

6. (a) R. Houriet, E. Rolli, G. Bouchoux and Y. Hoppilliard, Helv. Chim. Acta 68, 2037 (1985); (b) H. E. Audier and D. Robin, Org. Mass Spectrom. 21, 445 (1986); H. E. Audier, Y. Hoppilliard and D. Robin, Advances in Mass Spectrometry 1985 (Proc. 10th International Mass Spectrometry Conference 1985) ed. by J. F. J. Todd, Part B, p. 821. Wiley, Chichester (1986).

7. (a) B. Wilhalm, A. F. Thomas and F. Gautschi, Tetrahedron 20, 1185 (1964); (b) E. N. Givens, L. G. Alexakos and P. B. Venuto, Tetrahedron 25, 2407 (1969); (c) W. J. Richter, G. Liehr and P. Schulze, Tetrahedron Lett. 4503 (1972); (d) J. Vebrel, M. Roche and J. Gore, Org. Mass Spectrom. 12, 751 (1977).

8. A. G. Harrison, T. Gäumann and D. Stahl, Org. Mass Spectrom. 18, 517 (1983)

9. R. Spilker, Dissertation Universität Bielefeld (1987)

10. F. P. Lossing. A. W. Tickner and W. A. Bryce, J. Chem. Phys. 19. 1254 (1951)

11. M. J. S. Dewar and W. Thiel, J. Am. Chem. Soc. 99, 4899 (1977); W. Thiel, QCPE 4, 379 (1979).
12. J. Halim, N. Heinrich, W. Koch, J. Schmidt and G. Frenking, J. Comput. Chem. 7, 93 (1986).

13. H. M. Rosenstock, K. Draxl, B. W. Steiner and J. T. Herron, J. Phys. Chem. Ref. Data 6, Suppl. No. 1 (1977).

14. Strictly speaking, the chromylium ion $a$ in the mass spectra of 1 and 2 may also arise by an isomerization of the primarily formed methene benzofuranyl cations $b$ and $c$. However, it has been shown ${ }^{6 c}$ that furanyl ions and pyrylium ions do not interconvert in the gas phase. This is very likely true also for the benzo analogues discussed here. Work is in progress to confirm this hypothesis.

15. B. Schaldach and H.-Fr. Grützmacher, Int. J. Mass Spectrom. lon Phys. 31, 271 (1979).

16. An isotope effect $k_{H} / k_{D} \simeq 2$ has been observed for the $H(D)$ loss from metastable deuterated methyl furan ions ${ }^{5 a}$ approaching unity for ions energized by CA. Obviously the excess energy deposited by CA in the larger methyl benzofuran ions is not sufficient to override the discrimination of the D loss.

17. The $3 \mathrm{H}$-chromene ion $f$ is calculated to be surprisingly stable but has no stable neutral counterpart; $f$ can be viewed as a distonic ion in which the positive charge is delocalized while the radical electron is localized at $\mathrm{C}(2)$ (or vice versa!).

18. M. J. S. Dewar and K. M. Merz, Jr, J. Am. Chem. Soc. 107, $6111(1985)$

19. The chromylium ion a may be also formed by $\mathrm{H}$-loss from the $3 \mathrm{H}$-chromene ion $f$. However, the barrier for this process is similar to those for the $\mathrm{H}$-loss from $3^{+*}$ and $4^{+*}$, thus this fragmentation has been omitted from the MERPs.

20. S. Tanaka, J. Am. Chem. Soc. 73, 872 (1951).

21. D. I. Rawson, B. K. Carpenter and H. M. R. Hoffmann, J.Am. Chem. Soc. 101, 1786 (1979).

22. W. R. Boehme, Org. Synth. Coll. 4, 590 (1963).

23. E. H. Huntress and W. M. Hearon, J. Am. Chem. Soc. 63, $2762(1941)$

24. W. E. Parham and L. D. Huestis, J. Am. Chem. Soc. 84, 813 (1962).

25. J. W. Clark-Lewis and E. J. McGarry, Austr. J. Chem. 26, 819 (1973). 